\title{
柑桔黄龙病与类立克次体及 线状病毒的研究初报
}

\author{
柯 冲 林先沾 \\ （祢建省农业科学院果树研究所） \\ 陈 辉 陈元忠 章连钧 \\ （福州市工业科学技术研究所）
}

黄龙病是我国南方柑桔生产上的一种危险性病害, 半个世纪以来, 严重地危害着福建、广 东和广西三省区的柑桔事业的发展. 1956 年, 林孔湘 ${ }^{[1]}$ 根据嫁接传病的试䢔结果, 认为本病是 一种病毒病. 1965 年, 陈延熙等 ${ }^{[2]}$ 根据在指示植物上的测定结果, 认为本病就是衰退病 (Tristeza disease). 1974 年, 中国科学院上海生物化学研究所 ${ }^{[31}$ 采用聚乙二醇沉淀法, 从黄龙病病 树中分离出一种线状病毒, 大小为 $110-130 \times 25000-30000$ 埃. 他们认为这种线状病毒可 能是柑桔黄龙病的病原体或病原体之一. 最近, 由于广西柑桔黄龙病研究小组于 1976 年 ${ }^{[4]}$ 报 道发现四环素族抗菌素对此病有明显抑制或减轻症状的作用, 广东农林学院植保系植病组于 1977 年 ${ }^{[5]}$ 报道发现柑桔木虫是黄龙病的媒介昆虫. 不少人认为黄龙病的病原可能是一种类菌 原体 (Mycoplasmalike organism, 简称 MLO). 但是, 尚缺乏从病主柑桔的篮管细胞内找到 MLO 的直接证据. 从1976 年以来, 我们用电子显微镜进行研究, 发现病主植物笚管细胞内都含有 类立克次体 (Rickettsia-like organism, 简称 RLO), 而不一定含有线状病毒. 因而, 我们认为 黄龙病的病原是 RLO. 本文就是此项研究的结果报道.

\section{一、材料与方法}

本研究使用的材料是 6 株柑桔苗和 2 株相桔树. 柑桔苗是广西柑桔黄龙病研究小组种在 防虫网室内的试验苗木, 包括: (1) 四川鹅旦柑 (C. Sinensis Osbeck), 无症状; (2) 广西橙 (C. Sinensis Osbeck), 表现斑驭症状, 在尤力克柠檬 (C. limon〈L.〉Burm., Eureka lemon) 上测定均表现衰退病反应; (3) 改良橙 (可能是 $C$. Sinensis Osbeck $\times$ C. reticulata Blanco 的 无性杂种); (4) 哈姆林橙 (C. Sinensis Osbeck); (5) 科塞来檬 (C. aurantifolia 〈Chrislm〉 Swing)，均表现斑驭症状，在尤力克柠檬上测定均无表现衰退病反应; (6) 改良橙健株,在尤 力克柠檬上测定无表现衰退病反应, 作为对照. 这些苗木是 1975 年春以单芽切接法嫁接的. 除四川苼鸟旦柑的接穗采自四川重庆无黄龙病地区, 砧木是酸桔 (C.Sunki Hort.) 外, 其余的 种和栽培种的接穗是采自广西柳州病区，砧木是兰卜来檬 (C. limonia Osbeck). 1977 年秋, 上述苗木采用皮接法在指示植物尤力克柠榢上进行了衰退病的测定. (7) 福桔病树和 (8) 福 桔健树, 12 年生, 种在福州郊区建新公社台屿大队果林场内. 病树表现叶片叶脉黄化及黄绿 相间的斑驱症状.

在 1978 年 1-5 月间，我们从上述苗木和大树上分别取叶片的叶脉部分，切成 $1 \times 3-5$ 毫米的小块, 按常规方法在 5\% 戊二醛及 $2 \%$ 钱酸中固定, 经酒精系列脱水,包埋于 Epon 812

本文 1978 年 12 月 29 日收到。

第 10 期

科学 通 报 
中. 包埋块用 JUM-5 型超薄切片机, 以玻玹刀切片. 切片经铀盐和铅盐双染色后, 在 JEM7 型电子显微镜下观察。

\section{二、实验结果}

8 个样本组织的超薄切片, 在电子显微镜下观察的结果(见表 1 ).

表 1 柑桔 8 个样本组织超薄切片的观察结果*

\begin{tabular}{|c|c|c|c|c|}
\hline 样本 & 品＼cjkstart种 & 定 状 & 衰退病反应 & 观察结果 \\
\hline 1 & 四川秘旦柑 & - & + & 线状扊毒 \\
\hline 2 & 广西橙 & 斑政 & + & 线状病繁及 RLO \\
\hline 3 & 改良橙 & 玨㧞 & - & RLO 及线状病毒 \\
\hline 4 & 哈姆林橙 & 斑飘 & - & RLO \\
\hline 5 & 科塞来梅 & 玨软 & - & RLO \\
\hline 6 & 改良橙 & - & - & - \\
\hline 7 & 福桔 & 黄脉,玨驱 & 0 & RLO \\
\hline 8 & 福桔 & - & 0 & - \\
\hline
\end{tabular}

*“一”表示无症状、无衰退病反应或未观察到病原, “+”表示有衰退病反应, “听表示未测定.

（1）从样本 1 无症状表现的四川鹅旦柑幼苗的切片上, 观察到线状病毒质粒, 直径为 10-13 毫微米,具有空心结构(图 1、图 2).

（2）从样本 2 广西橙病苗的切片上, 观察到线状病毒质粒和 RLO. 线状病毒质粒的直径 为 10-13 毫微米, 与从四川鹅旦柑上观察的线状病毒质粒相同. RLO 是多形态的. 由于切 片方向的不同,在切片上观察到的 RLO 多数呈圆形或椭圆形, 少数呈线状或不规则形, 大小 为 50-600 × 170-1600 毫微米(图 3、图 4). 其外围的单位膜是由三层膜构成, 内、外层的 电子密度较浓, 而中间层的电子密度较稀, 厚度为 17-33 毫微米. 内部含有似核糖蛋白体质 粒及似脱氧核糖核酸线体的构造(图 5). 在本样本的切片上, 含有线状病毒质粒或 RLO 的 细胞数比其他样本切片上的多, 各占观察细胞总数的 $10 \%$ 左右. 在同一切片上, 含有线状病 毒质粒或 RLO 的细胞有时相隔甚远, 有时是相邻的细胞, 但还未观察到同一细胞内同时含有 RLO 和线状病毒质粒.

（3）从样本 3 改良橙病苗的切片上观察到 RLO, 也观察到线状病毒质粒. 但是, 在本样 本切片上,观察到含 RLO 的细胞数比含线状病毒质粒的细胞数较多.

(4) 从样本 4 哈姆林橙和样本 5 科塞来檬的病苗的切片上,均观察到 RLO, 但未观察到 线状病毒质粒.

（5）从样本 6 改良橙健苗和样本 8 大田福桔健树的切片上, 均未观察到 RLO 或线状病 毒质粒.

（6）从样本 7 大田福桔病树的切片上观察到 RLO, 但末观察到线状病毒质粒.

（7）在上述各病株样本的切片上, RLO 或线状病毒质粒主要分布在韧皮部的管管 细胞 和薄壁细胞中. 在伴胞内亦发现线状病毒质粒,但未发现 RLO.

（8）在含 RLO 的细胞中, 不论 RLO 的数量多或少, 其细胞质和细胞器往往都消失掉, 


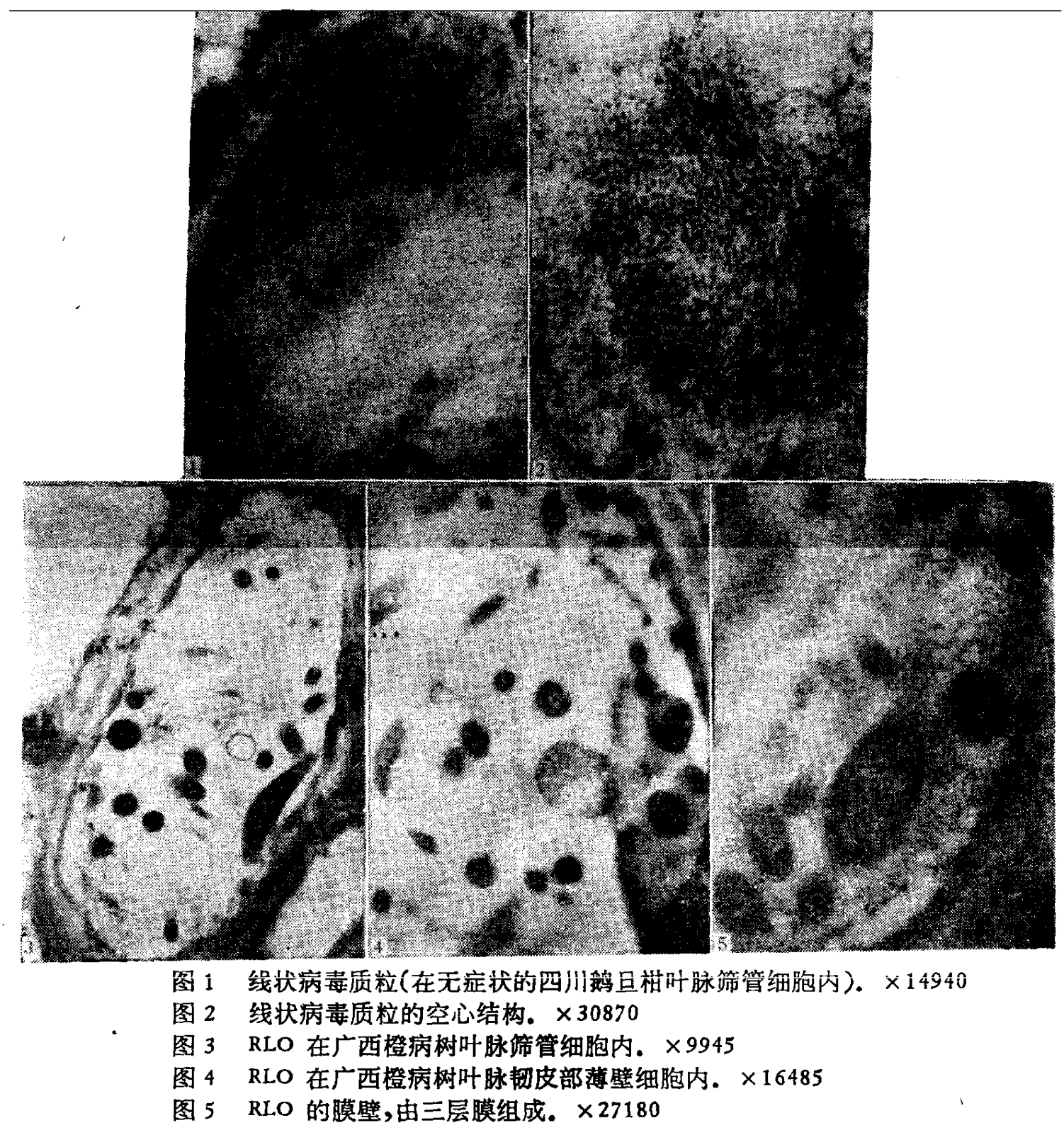

而在含线状病毒质粒的细胞中, 则多能观察到细胞质和线粒体. 只有当线状病毒质粒充满整 个细胞时,它们才完全消失掉.

\section{三、讨 论}

上述电子显微镜观察结果：从感染黄龙病的柑桔类各个种和栽培种（包括广西橙、改良 橙、哈姆林橙和科塞来檬的幼苗及福桔成年树) 的病株切片上, 在其㓞皮部组织的篮管细胞和 薄壁细胞内,均发现 RLO; 而在健康的改良橙幼苗和福桔成年树的切片上则未发现 RLO, 表 明 RLO 与黄龙病有着密切的关系.

关于黄龙病病株上的 RLO 的病原性问题，应该按科赫法则 (Koch's Postulate) 的要求进 一步研究才能确定. 但是, 自从 Doi 等 ${ }^{[6]}$ 发现 MLO 是植物黄化、鬼帚类病害的病原以来, 各 国相继报道的植物 MLO 类病害 [包括螺原体 (Spiroplasma) 和 RLO 所致的病害在内] 将近 100 种, 但至今能用人工培养法成功培养提纯并经科赫法则鉴定的病例为数极少, 只有柑桔顽 固病 ${ }^{[7]}$ 、玉米矮缩病 ${ }^{[8]}$ 和三叶草变叶病 ${ }^{[91}$ 等。由于这类病害的病原体不容易分离和人工培养的 
缘故,目前各国在鉴定上多采用下列二个标准：首先, 在病主植物的管管细胸内, 用电子显微 镜观察到病原体 ${ }^{[6]}$. 其次,四环素族抗菌素能抑制或减轻症状的表现 ${ }^{[10]}$. 按照这个标准, 由于 本研究已证明在柑桔病主的篮管细胞内存在 RLO, 而广西柑桔黄龙病研究小组 ${ }^{[4]}$ 亦已证明盐 酸四环素注射病树能减轻或暂时抑制症状的表现. 所以我们初步认为我们观察到的 RLO 就 是柑桔黄龙病的病原.

在形态上, RLO 区别于 MLO 和螺原体的主要特征在于其膜壁较厚和外膜厚薄不均. 据报道 RLO 的单位膜比较厚,其中为害㓞皮部的为 20 毫微米,为害木质部的比为害韧皮部的 厚 5-10 倍; 而 MLO 和螺原体的单位膜则比较薄,一般厚度为 7.5-10 毫微米 ${ }^{[11,12]}$. 本研究 观察到的黄龙病病原体的单位膜比较厚, 为 17-33 毫微米, 而且外层膜具有厚薄不均匀的表 现. 这种单位膜形态不象细胞膜, 而象细胞壁. 因此, 我们认为, 在得到进一步的生理生化等 试验结果之前,把柑桔黄龙病这种病原微生物暂时归属于 RLO 类较为恰当.

本实验从表现斑驳的广西橙及无症状的四川鹅旦柑幼苗上观察到线状病毒, 其质粒的直 径为 10-13 毫微米, 且具有典型线状病毒的中空结构. 这与 Price ${ }^{[13]}$ 在感染衰退病的墨西哥 来檬 (C. aurantifolia 〈christm〉Swing) 组织超薄切片上所观察的衰退病毒,大小、形态上都十 分相似. 同时,四川鹅旦柑及广西橙的组织接种在尤力克柠檬上均表现衰退病反应. 所以,我 们认为线状病毒是属于柑桔衰退病毒类的一种病毒.

本实验从表现黄龙病症状的广西橙(样本 2) 和改良橙(样本 3) 的切片上, 观察到 RLO 和线状病毒, 但从表现黄龙病斑驱症状的哈姆林橙(样本 4), 科塞来檬(样本 5) 和表现黄龙病 斑驭和黄脉的福桔树 (样本 7) 的切片上, 都只观察到 RLO, 而从无症状的四川鹅旦柑 (样本 1)、改良橙(样本 6) 和福桔树(样本 8) 的。切片上则皆未观察到 RLO. 这个事实表明 RLO 能 单独引起黄龙病, 而线状病毒则不能, 也就是说黄龙病的病原是 RLO 而不是线状病毒. 至于 两者同时侵染柑桔时的症状和为害是否会加重,则有待于进一步调查研究。

改良橙病苗(样本 3) 表现斑驳, 用尤力克柠檬测定无表现衰退病反应, 但在其切片上除观 察到 RLO 外, 也观察到线状病毒. 我们认为, 这可能是在尤力克柠檬接种上的试验误差问 题. 因为在嫁接传病实验上,传病成功率通常并不是百分之百的.

致谢：本文蒙华南农学院范伓忠教授提供宝贵意见，广西柑桔黄龙病研究小组赠送试验材料，特此致 谢.

\section{考文 献}

[1] 林孔湘, 植物病理学报, 2 (1958), 13-42.

[2] 陈延黙、梅汝鸿, 植物保护学报, 4 (1965), 361-363.

[3] 中国科学院上海生物化学研究所病毒组, 中国科学, 1973, 3: 313-325.

[4] 广西柑桔黄龙病研究小组, 柑枯科技通讯, 1976, 2: 28一-31.

[5] 广东农林学院植保系植病教研组, 广东农业科学, 1977, 6: 50-51, 53 .

[6] Doi, Y., Teranaka. M., Yora. K. \& Asuyama, H., Ann. Phytopath. Soc. Japan, 33(1967), $259-266$.

[ 7 ] Fudl-Allah, A. E. A. \& Calavan, E. C., Phytopoth., 63(1973), 256-259.

[ 8 ] Chen, T. A. \& Liao, C. H., Science (Wash.), 138(1975), 1015-1017.

[ 9$]$ Faivre-Amiot, et al., Annales de Phytopathologie, 2 (1970), 251.

[10] Ishüe, T., Doi, Y., Yora, K. \& Asuyama, H., Ann. Phytopath. Soc. Japan, 33(1967), $267-275$.

[11] Freundt, E. A., In Bergey's Manual of Determinative Bacteriology, Eighth Edition, Williams \& Wilkins, Baltmore, 1974, 929-954.

[12] Maramoroch, K., In Encyclopedia of Plant Physiology (New Series Volume 4), Springer-Verlag, Berlin, Heidelberg, New York, 1976, 150-171.

[13] Price, W. C., Virology, 29(1966), 285-294. 